\title{
Article
}

\section{An Efficient and Cost-Effective Nose-Only Inhalational Chamber for Rodents: Design, Optimization and Validation}

Kaur, Ranjot, Kaushik, Anupama, Singh, Kamalinder, Katare, O P and Singh, Bhupinder

Available at http://clok.uclan.ac.uk/31618/

Kaur, Ranjot, Kaushik, Anupama, Singh, Kamalinder ORCID: 0000-0001-73250711, Katare, O P and Singh, Bhupinder (2020) An Efficient and Cost-Effective Nose-Only Inhalational Chamber for Rodents: Design, Optimization and Validation. AAPS PharmSciTech, 21 (3). p. 82.

It is advisable to refer to the publisher's version if you intend to cite from the work. http://dx.doi.org/10.1208/s12249-019-1608-4

For more information about UCLan's research in this area go to http://www.uclan.ac.uk/researchgroups/ and search for <name of research Group>.

For information about Research generally at UCLan please go to http://www.uclan.ac.uk/research/

All outputs in CLoK are protected by Intellectual Property Rights law, including Copyright law. Copyright, IPR and Moral Rights for the works on this site are retained by the individual authors and/or other copyright owners. Terms and conditions for use of this material are defined in the policies page. 


\section{An Efficient and Cost-effective Nose-only Inhalational Chamber for Rodents: Design, Optimization and Validation}

Ranjot Kaur ${ }^{1,3}$, Anupama Kaushik ${ }^{2}$, Kamalinder K. Singh $^{3}$, O.P. Katare ${ }^{1}$, Bhupinder Singh*1,4

${ }^{1}$ University Institute of Pharmaceutical Sciences, UGC Centre of Advanced Studies, Panjab University, Chandigarh, India 160014

${ }^{2}$ Dr. S.S. Bhatnagar University Institute of Chemical Engineering and Technology, Panjab University, Chandigarh, India 160014

${ }^{3}$ School of Pharmacy and Biomedical Sciences, University of Central Lancashire, Preston, United Kingdom PR1 2HE

${ }^{4}$ UGC-Centre of Excellence in Applications of Nanomaterials, Nanoparticles and Nanocomposites (Biomedical Sciences), Panjab University, Chandigarh, India 160014

*Corresponding author email: bsbhoop@pu.ac.in, bsbhoop@yahoo.com

*To whom correspondence should be addressed

Professor Bhupinder Singh Bhoop

M Pharm, Ph D, D St, FPAS, FIPA

Coordinator, UGC Centre for Excellence in Nano-Biomedical Applications

Coordinator, UGC Centre of Advanced Studies in Pharmaceutical Sciences

University Institute of Pharmaceutical Sciences

Panjab University, Chandigarh 160 014, India

E-mail: bsbhoop@yahoo.com, bsbhoop@pu.ac.in

+91 172 2534103, Fax: +91 1722543101

Running head title: Nose-only inhalational chamber for rodents 


\section{ABSTRACT}

The mainstay treatment of pulmonary disorders lies around the direct drug targeting to the lungs using a nebulizer, metered-dose inhaler, or dry powder inhaler. Only few inhalers are available in the market that could be used for inhalational drug delivery in rodents. However, the available rodent inhalers invariably require high cost and maintenance, which limits their use at laboratory scale. The present work, therefore, was undertaken to develop a simple, reliable and cost-effective nose-only inhalation chamber with holding capacity of three mice at a time. The nebulized air passes directly and continuously from the central chamber to mouthpiece and maintains an aerosol cloud for rodents to inhale. Laser diffraction analysis indicated volume mean diameter of $4.02 \pm 0.30 \mu \mathrm{m}$ and the next-generation impactor studies, however, revealed mean mass aerodynamic diameter of $3.40 \pm 0.27 \mu \mathrm{m}$, respectively. An amount of $2.05 \pm 0.20$ mg of voriconazole (VRC) was available for inhalation at each delivery port of the inhaler. In vivo studies indicated the deposition of $76.12 \pm 19.50 \mu \mathrm{g}$ of VRC in the mice lungs when nebulized for a period of 20 minutes. Overall, the developed nose-only inhalation chamber offers a reliable means of generating aerosols and successfully exposing mice to nebulization. KEYWORDS: Nebulizer, Aerosols, Voriconazole, Preclinical, Spraytec.

\section{INTRODUCTION}

Inhalational drug delivery has been gaining immense importance in the treatment of various respiratory disorders for the last two decades. It offers distinct advantages of rapid onset of action, thin epithelial barrier, reduced dosage amount, localized action, avoidance of first-pass effect and gastrointestinal (GI) problems (1-3). A wide range of inhalational devices like nebulizers, dry powder inhalers (DPIs) and metered dose inhalers (MDIs) are available in the market to deliver drug molecules effectively to the human lungs (4-6). However, the availability of inhalation devices for carrying out the preclinical testing in rodents of drug therapeutics or their novel formulations at laboratory scale is quite limited. 
Majorly, two types of inhalation exposure chambers, viz., whole-body exposure and head/noseonly exposure have been employed in the preclinical testing of inhalational drug products (79). Other direct instillation methods, like intratracheal instillation or dry powder insufflation, have also been used by the researchers to introduce the drug therapeutics directly to the lungs $(10,11)$. Nevertheless, these commercially available rodent inhalers are too costly to meet up the standard laboratory requirements, particularly for scientists working in developing countries. To overcome such issues, some of the researchers have built their in-house inhalers in order to conduct preclinical testing in rodents (12-15). The initial in-house models reported in the literature consisted of glass bottles, where the rodents were placed either inside the bottles (16) or in a side-exit of the bottle for inhalation (17). Tests were also conducted using inhalation boxes, where cotton pieces or filter disks moistened with test material were placed and fixed inside the box for inhalation by the rodents $(18,19)$. Some researchers have also used squareshaped or cylindrical inhalation chambers, connected with nebulizers, for the generation of an aerosol cloud for inhalation $(20,21)$.

Development and validation of a nose-only inhalation chamber for mice was reported by Kaur et al. (2008) for delivering microparticles (MPs) of rifabutin in the form of dry powder (10). Out of the $20 \mathrm{mg}$ of fluidized MPs, about $2.5 \mathrm{mg}$ were collected at the delivery port in $30 \mathrm{~s}$ of operation, but only $61.5 \mu \mathrm{g}$ of drug was inhaled by the mice. Albeit the design of the inhaler was quite simple and easy to fabricate, yet it suffered from serious limitations of inconsistency (being manually operated) and time-consumingness (being applicable for one animal at one time). Subsequently, Yi et al. (2013) fabricated and validated a whole-body exposure chamber to study the toxicity profile of titanium oxide nanoparticles (NPs) in rodents (22). The inhalation chamber consisted of an aerosol generator, exposure chamber and a monitoring system. The aerosols, generated from dry powder containing NPs were delivered to the exposure chamber at a flow rate of 90 liters per minute. Despite the attainment of controlled and uniform aerosol 
atmosphere of NPs during the whole process of inhalation exposure, several drawbacks were associated with this type of inhalation chamber. These encompassed the use of a large amount of formulation or drug being tested, aerosol exposure to other parts of rodent like skin or fur, and acute requirement of excellent mixing for attaining uniform distribution of aerosol within the chamber $(1,23)$. Sinha et al. (2013) also developed a nose-only inhalation chamber for dry powder insufflation and nebulization taking six rodents at one time (13). The inhalation chamber was made up of centrifuge tubes and a polypropylene-rectangular box, employing voriconazole (VRC; in solution and micronized form) as a model drug. In vivo drug deposition was found to be significantly higher in case of DPI (i.e., $80-130 \mu \mathrm{g} / \mathrm{g}$ ) vis-à-vis the nebulizer (i.e., 40-68 $\mu \mathrm{g} / \mathrm{g}$ ). The developed inhaler, however, had limitations of large inhalation chamber and inability to keep the holding chambers at equidistant levels from the inlet (i.e., DPI or nebulizer), resulting eventually in uneven distribution of the inhalable dose. Recently, Silva et al. (2017) developed and evaluated a round-wall glass inhalation chamber for preclinical testing in rodents connected to a nebulizer on the upper side and animal holders the lower side (24). Activation of the nebulizer passed air directly from the central portion to the holding chambers, while the vapors within the chamber were collected and analyzed using gas chromatography. Significant loss, however was noticeable, ostensibly owing its large central chamber $(\sim 8 \mathrm{~cm}$ area), thus limiting its usage for the aerosolization of expensive drugs. Besides inhalation of drugs, nose-only inhalation chambers have also been reported for the rodents for nebulizing chronic wasting disease prions, infective bioaerosols and aqueous solutions of radiolabelled human serum albumin formulation $(12,25,26)$. Various pitfalls associated with these inhalation chambers included complex and costly design set-up and difficulty to emulate the same at laboratory levels.

The present research work, thus accordingly was undertaken to develop a simple, efficient, reliable, reproducible and low-cost nose-only inhalation exposure system with an aim to 
minimize the aerosol loss in the central chamber and to meet up the standard requirements of preclinical testing at the small-scale laboratory. The developed inhalation chamber was evaluated and validated using in vitro and in vivo tests both, employing VRC as the model drug.

\section{MATERIALS AND METHODS}

\section{Instrument and Reagents}

The jet nebulizer was procured from Philips, New Delhi, India. Centrifuge tubes (50 mL) were purchased from Tarsons, New Delhi, India. VRC was generously supplied as a gift sample by M/s Panacea Biotech, New Delhi, India. The HPLC-grade solvents, viz., acetonitrile (ACN) and methanol, were purchased from M/s Fisher, New Delhi, India. All other chemicals used were of high purity or analytical grade and were employed as such obtained.

\section{Design of Inhalation Chamber}

Based on the know-how gained from the previous inhaler reports, the nose-only inhalation chamber was designed using readily available objects. The low-cost inhalation chamber consisted of five major parts, a) nebulizer as aerosol generator; b) a three-way splitter as central chamber; c) flexible tubing as a linker, i.e., connect nebulizer to three-way splitter; d) a small rectangular vial (5.5 cm length, $3 \mathrm{~cm}$ diameter) as mouthpiece for rodents and e) centrifuge tubes $(50 \mathrm{~mL})$ as mice holding chambers or restrainers.

\section{Analytical and Bioanalytical Method Development}

Analysis of VRC was performed as per the analytical method developed and validated in our laboratory using a mobile phase consisting of $\mathrm{ACN}$ and acetic acid solution (50:50), at a flow rate of $1 \mathrm{~mL} / \mathrm{min}$. The entire analysis was conducted employing a reversed-phase $\mathrm{C}_{18}$ column, 250 x $4.6(\mathrm{~mm})$ with a particle size of $5 \mu \mathrm{m}$ (Purospher® STAR, Merck) and a PDA detector using a wavelength of $256 \mathrm{~nm}$ under isocratic conditions.

A standard stock solution of VRC $(10 \mathrm{mg} / \mathrm{mL})$ was prepared in methanol: water (1:1), which was further diluted to obtain a drug concentration of $100 \mu \mathrm{g} / \mathrm{mL}$. Various working standard 
solutions i.e., $0.1-50 \mu \mathrm{g} / \mathrm{mL}$ were serially prepared from the stock solution $(100 \mu \mathrm{g} / \mathrm{mL})$. For bioanalytical estimation, an aliquot of $200 \mu \mathrm{L}$ of lung homogenate was added to $200 \mu \mathrm{L}$ of working standard solutions with volume make up to $1 \mathrm{~mL}$ using $\mathrm{ACN}$. The mixture blend was vortexed, centrifuged and filtered through a $0.22 \mu \mathrm{m}$ syringe filter prior to subjecting for HPLC analysis.

\section{Determination of Microdroplet Size of an Aerosol}

The microdroplet size of an aerosol was measured using the Spraytec laser diffraction instrument (Malvern Instruments, UK), equipped with a He-Ne laser. A lens with a focal length of $300 \mathrm{~mm}$ was used covering microdroplet size between 0.1 and $900 \mu \mathrm{m}$. Briefly, $5 \mathrm{~mL}$ of the sample was loaded on to the jet nebulizer and placed perpendicularly to the laser lens line of the instrument at a distance of $3 \mathrm{~cm}$ from the laser beam (27). The values of volume mean diameter (VMD), geometric standard deviation (GSD) and the fine particle fraction (FPF) were computed using the Spraytec version 3.20 software after passing aerosol droplets through the laser beam (28).

\section{Determination of Pulmonary Deposition by Next-Generation Impactor}

Pulmonary deposition studies were performed using a Next-Generation Impactor (NGI) at a flow rate of $15 \mathrm{~L} /$ minute (29). The nebulizer was connected to the induction port of NGI (COPLEY Scientific, UK) with a mouthpiece adapter, filled with $5 \mathrm{~mL}$ of inhalation solution with an aerosol collection time of 5 minutes. Once the measurement was completed, the cup holder tray was removed and each of its stages was washed with $10 \mathrm{~mL}$ of extraction solvent (i.e., methanol), filtered and subjected to HPLC analysis for determining the VRC content at each stage of the impactor. The mass median aerodynamic diameter (MMAD) and geometric standard deviation (GSD) were calculated using online MMAD calculation software (30). Emitted dose (ED), i.e., the total amount of drug emitted from the inhaler device and fine 
particle fraction (FPF), i.e., the ratio of the mass of particles less than $5 \mu \mathrm{m}$ to the emitted dose, was also calculated (31).

\section{Determination of Nebulized Air-Flow at Each Delivery Port}

The nebulized airflow reaching each delivery port was determined with the help of a gas flow meter MGF 505 (Metrex, New Delhi, India). The flow meter was attached to one of the three outlets of the central chamber, with the rest of the two outlets closed with the help of a glass stopper. The airflow value of all the three delivery ports was determined in order to confirm the uniformity of airflow during operation (24).

\section{Determination of Dose Available for Inhalation}

The initial characterization of the exposure chamber was performed using pre-weighed cotton balls $(250.12 \pm 13.09 \mathrm{mg})$, placed close to the delivery port of the holding chambers $(10)$. Different concentrations of VRC $(1-3 \mathrm{mg} / \mathrm{mL})$ in a solution of normal saline were nebulized for a period of 20 minutes. During operation, the surface of the cotton ball was exposed to the aerosol generated from the nebulizer. After corresponding periodic time-intervals, the nebulizer was turned-off, the balls were removed using forceps from the tube and were weighed on a precision analytical balance (Mettler Toledo ME204, Ohio, USA). Furthermore, VRC was estimated quantitatively employing an HPLC-based analytical technique after soaking the cotton ball in a solvent blend of methanol and water $(1: 1)$ for $2 \mathrm{~h}$, followed by bath sonication for 10 minutes and filtration using $0.22 \mu \mathrm{m}$ filters. Once the amount of the VRC at each delivery port was confirmed, the performance of the developed inhalation chamber was further tested in the animals studied.

\section{Validation of Inhaled Voriconazole in Balb/c Mice}

The animal experiments were carried out after obtaining the requisite ethical approval from the Institutional Animal Ethics Committee of Panjab University, Chandigarh, India (PU/45/99/CPSEA/IAEC/2019/243). Balb/c mice weighing $23 \pm 2 \mathrm{~g}$, were procured and 
provided with a standard diet and water ad libitum. Prior to each experiment, mice were fasted for $12 \mathrm{~h}$ with free access to water. Animals received nebulization of $3 \mathrm{mg} / \mathrm{mL}$ of VRC (Vorier, Aspiro Pharma, Telangana, India) for a period of 20 minutes. During the experiment, the test solution was aerosolized using a jet nebulizer, i.e., Philips Respironics InnoSpire compressor nebulizer with a volume capacity of $15 \mathrm{~mL}$. Ten milliliters of VRC solution in normal saline (3 $\mathrm{mg} / \mathrm{mL}$ ) was placed into the nebulizer fluid cup, mice were loaded into the apparatus and the entire chamber was placed in a secondary enclosure in a well-vented room. The aerosol generated by the nebulizer entered the central chamber and reached the delivery port. Each animal was positioned in such a way that the nose of the mice was exposed to the delivery port. The air exhaled by the animal escaped from the mouthpiece via a small opening present at the upper wall near the apex. As the central chamber and mouthpiece were airtight, no air entered or left the exposure system except via the aerosol delivery and exhaust. At specified time intervals of $0.5,2$ and $6 \mathrm{~h}$, animals $(\mathrm{n}=3)$ were sacrificed by cervical dislocation, the lungs were removed, homogenized in PBS $7.4(5 \mathrm{~mL})$ for 5 minutes employing a tissue homogenizer (Heidolph, RZR 2011, Germany) and stored at $-20^{\circ} \mathrm{C}$ until analyzed. At the time of experiment, the samples were thawed and $200 \mu \mathrm{L}$ of lung homogenate was added to $1 \mathrm{~mL}$ of ACN followed by vortexing for 20 minutes. The samples were centrifuged for 10 minutes at 10,000 rpm (9055 $\times \mathrm{g})$ and the supernatant was then filtered through $0.22 \mu \mathrm{m}$ syringe filters prior to HPLC analysis. The percent drug deposition in lungs in vivo was measured by dividing the total VRC deposited in the lung tissue with the amount of drug available for inhalation at the delivery ports, obtained during the in vitro studies.

\section{Statistical Analysis}

Values were listed as means \pm SD. Statistical comparison of means was performed by unpaired Students t-test and one-way ANOVA. Statistical analysis was performed using GraphPad Prism, Version 4.03. 
175 RESULTS AND DISCUSSIONS

176 Design of Inhalation Chamber

177 The development of a low-cost nose-only inhalation chamber started with a review of various 178 inhaler devices reported in the literature to date $(12,14,25,26,33-35)$. After analyzing the data, 179 a final sketch of the model equipment was prepared with an aim to minimize the aerosol loss in 180 the central chamber (i.e., connect nebulizer to animal restrainer), preferably using readily 181 available, inexpensive, easy to disassemble and clean objects.

182 In order to design the apparatus for use by three animals at a time and to minimize the drug 183 wastage, a three-way splitter (Fig. 1) of diameter $1 \mathrm{~cm}$, approximately 8-fold less than the 184 recently developed inhaler (24), was used as the central chamber. The trifurcations of the central 185 chamber were placed at the equidistant levels from the inlet to ensure uniformity in the dose 186 delivered to each mouthpiece and ultimately to the delivery ports of the animal restrainers. 187 Moreover, the small size of the central chamber reduced the time required for its saturation, 188 thus economizing both time as well as drug amount. A small rectangular vial was used as a 189 mouthpiece that was connected to each outlet of the central chamber. A small hole or vent was 190 also made in the wall of each mouthpiece, near the rim of the screw cap, in order to minimize any pressure build-up inside the aerosol chamber. 


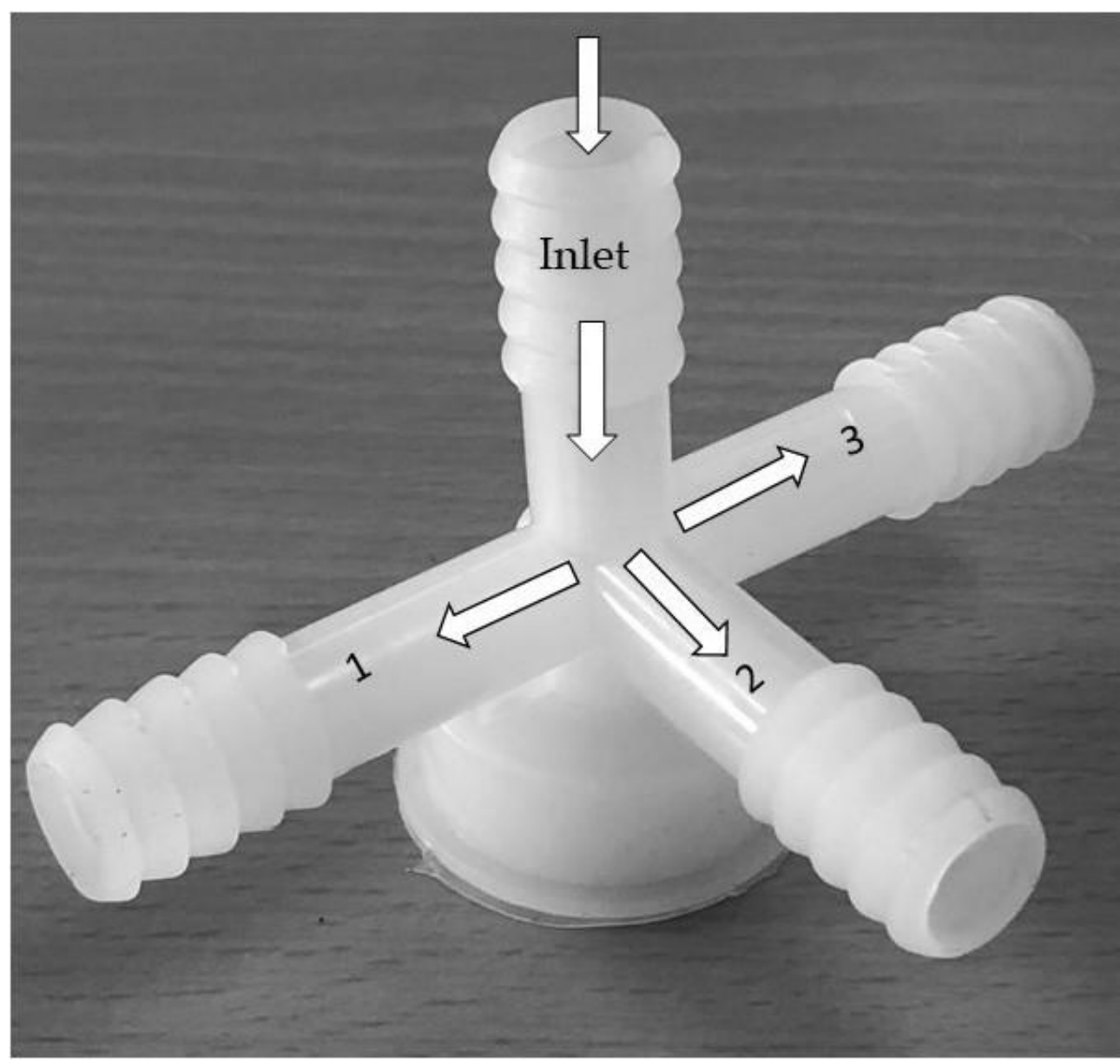

Fig. 1. A three-way splitter as central chamber depicting the flow pattern of the aerosol.

Centrifuge tubes with a diameter of $1.8 \mathrm{~cm}$ were used as the mouse-holding chambers or restrainers, as these are routinely used in the laboratories and are small enough to prevent any plausible change in the direction of movement by the animals. Moreover, their cylindrical structure with a narrow front and large aperture at the distal part allowed easier introduction and removal of an animal weighing $23 \pm 2 \mathrm{~g}$. The tips of the centrifuge tubes were removed to make a hole of around $0.9 \mathrm{~cm}$ diameter, so that nose of the mouse can easily be inserted into these. Care was exercised to leave a smooth edge to avoid any discomfort to the animal. The holding chambers were designed in such a way that mainly the nose of the mouse was exposed to the aerosol cloud, as shown in the photograph (Fig. 2). The animals were restrained with the help of cotton within the animal holders. 


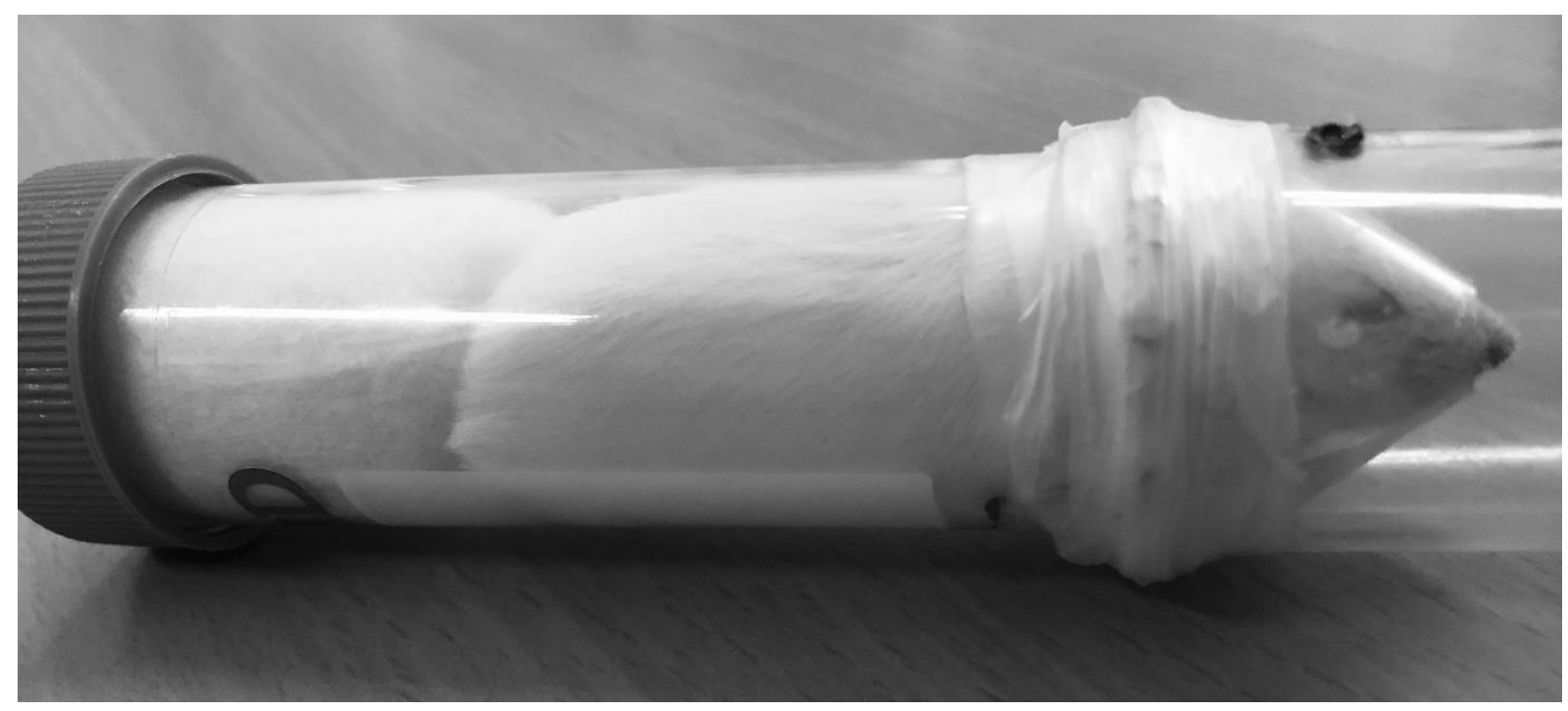

Fig. 2. Aerosol-exposure to mice in the holding chamber.

A flexible tubing, with $25 \mathrm{~cm}$ length and $1.2 \mathrm{~cm}$ diameter, was employed to connect the mouth of the nebulizer with the central portion of the three-way splitter. It serves the purpose of transferring the mist generated from the nebulizer to the delivery port through the central chamber. The fabrication of the inhalation chamber is depicted in the photograph (Fig. 3). The compressor attached to the nebulizer provides a positive pressure of $12.1 \pm 1.2$ psi for the generation of an aerosol mist. After the final assemblage, the inhalation chamber was checked for any leakage by nebulizing it with distilled water. Any leaks detected were sorted and fixed until the instrument was flawlessly leak-proof. 


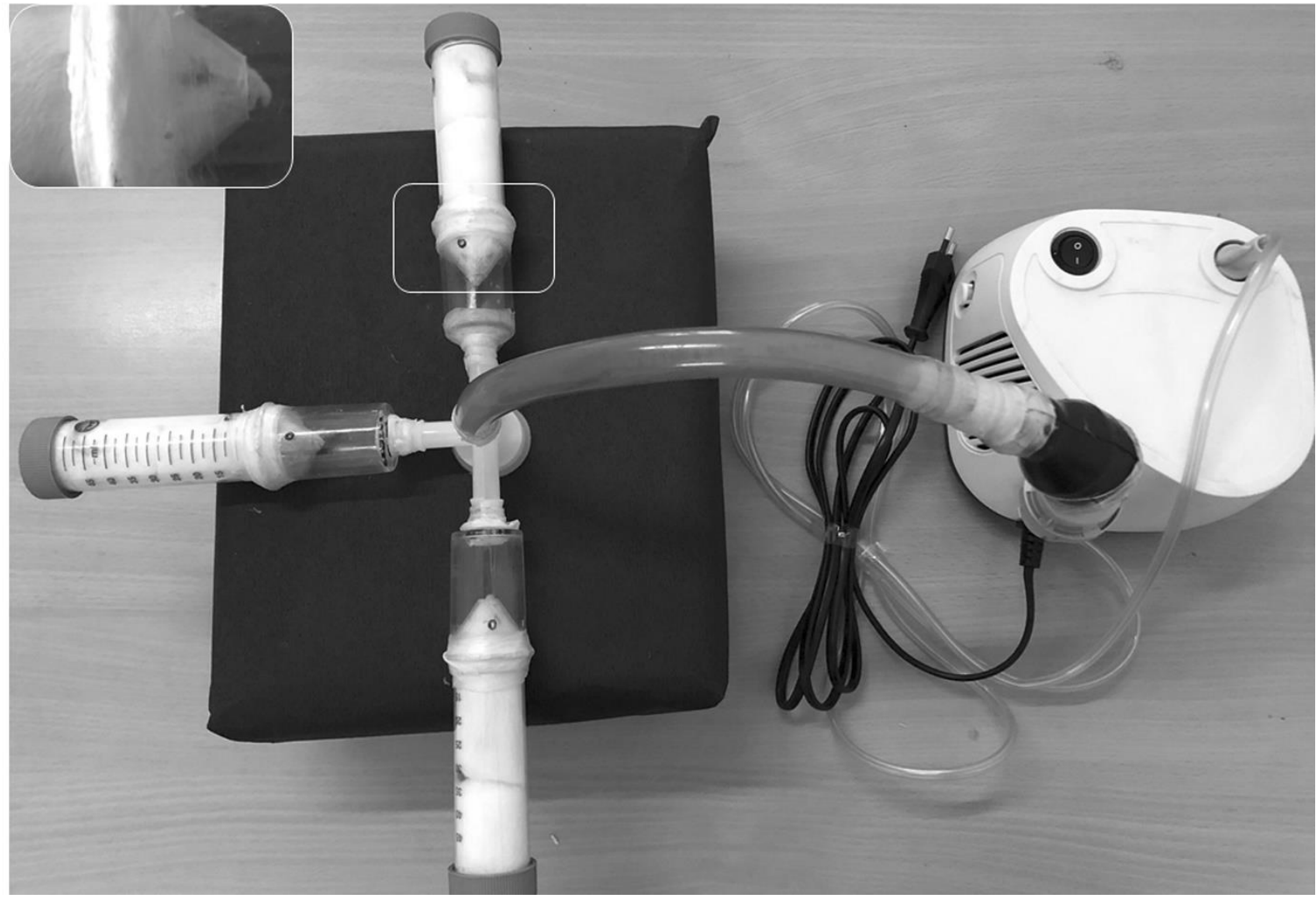

Fig. 3. Design of the inhalation chamber coupled with a nebulizer.

\section{Analytical and Bioanalytical Method Development}

217 Linear calibration curves were generated with working standards for the quantification of VRC

218 in cotton balls and in the lungs. Validation of linearity range was carried out by constructing

219 the residuals plots (inset), which indicated the percent deviation in responses, well within $\pm 5 \%$

220 limit of the working VRC concentrations as illustrated in Fig. 4 (A, B). A chromatogram 221 showing the peak of VRC in methanol: water and in lung homogenate is illustrated in Fig. 5 $222(\mathrm{~A}, \mathrm{~B})$. 

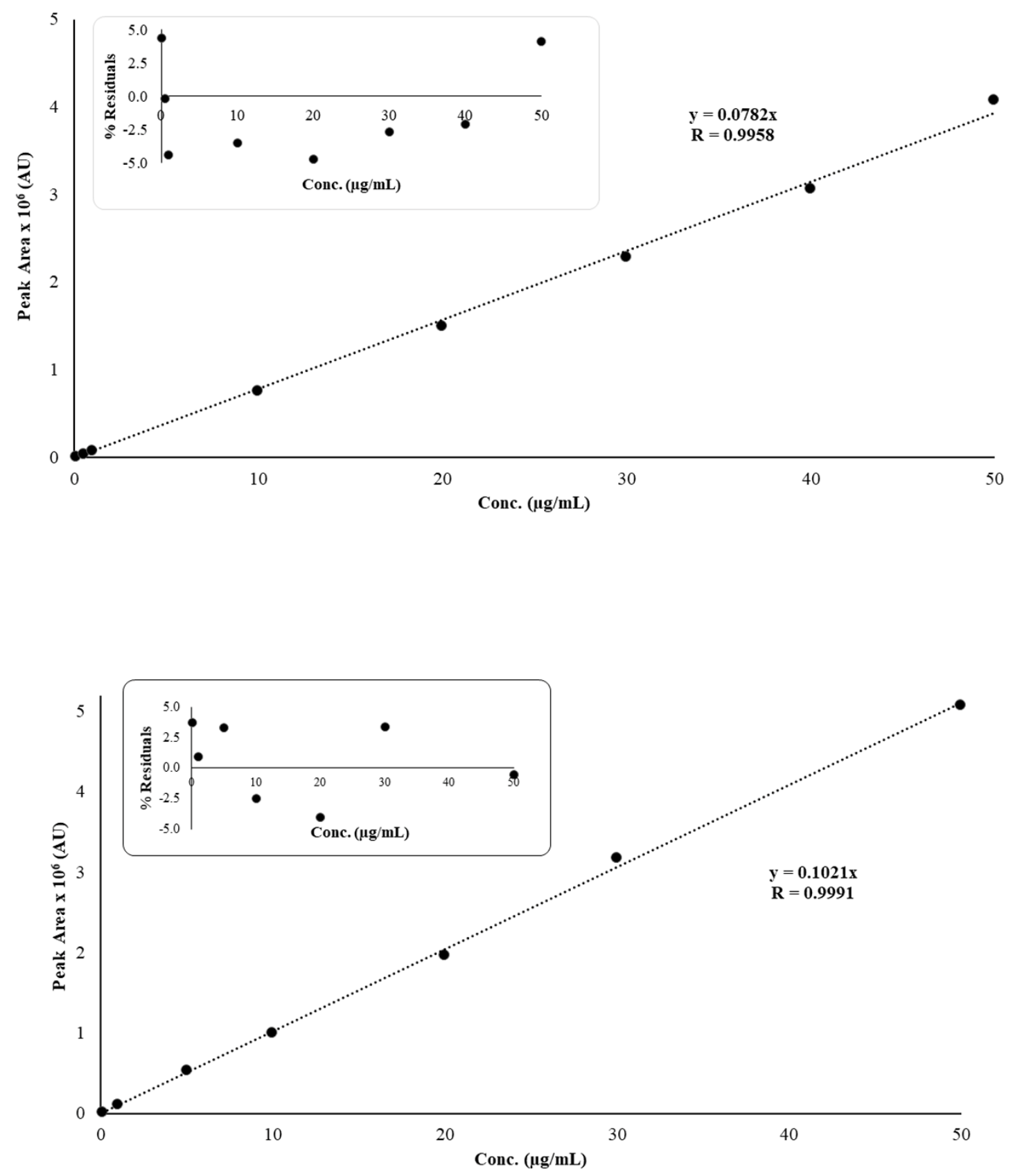

225 Fig. 4: Calibration plot of VRC in A) methanol: water and B) lung homogenates. The inset depicts the corresponding residual curves. 

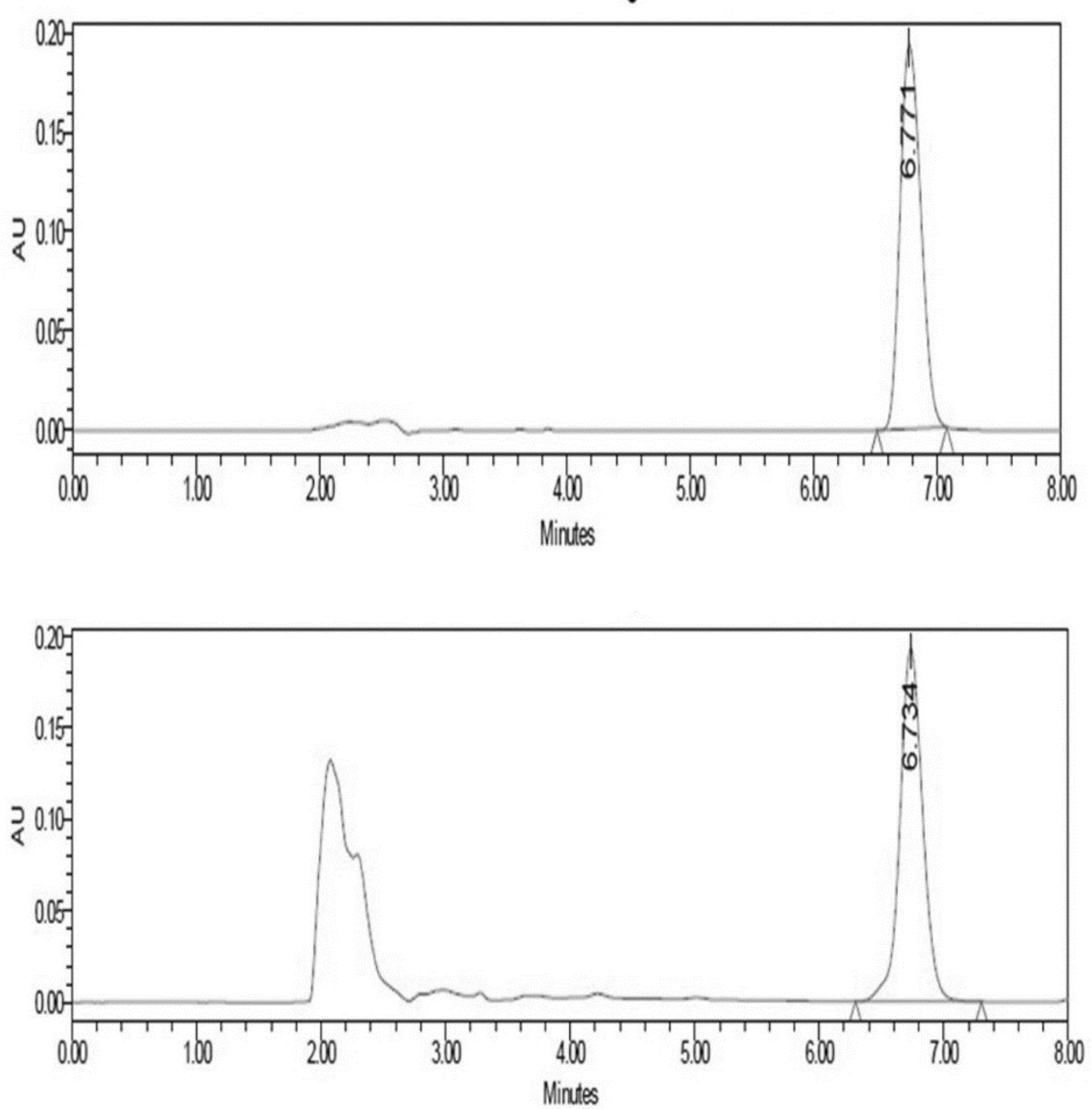

Fig. 5. The chromatogram of voriconazole in (A) methanol: water (B) lung homogenates.

\section{Determination of Microdroplet Size of Aerosol}

Fig. 6 represents the frequency and cumulative volume distribution profile of the aerosol generated through a jet nebulizer. Laser diffraction analysis yielded a VMD of $4.02 \pm 0.30 \mu \mathrm{m}$ and GSD of $1.79 \pm 0.02 \mu \mathrm{m}$. The proportion of microdroplets with a diameter below $5 \mu \mathrm{m}$, i.e., the fine-particle fraction (FPF), was found to be $62.62 \pm 0.45 \%$. Thus, VMD of less than $5 \mu \mathrm{m}$ depicts the potential of the generated aerosol to deposit in the lungs. 


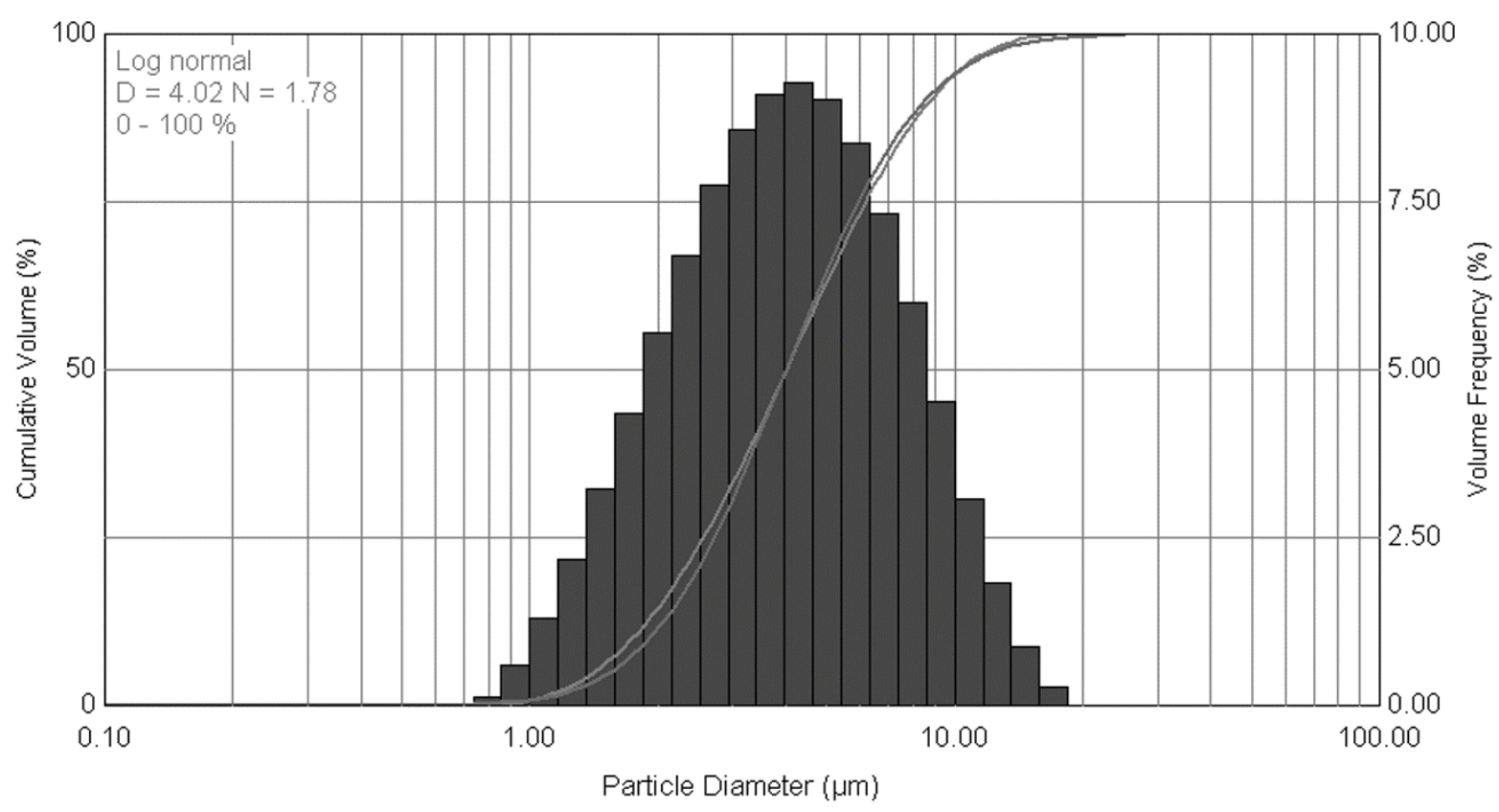

Fig. 6: Particle size distribution of voriconazole microdroplets.

\section{Particle Deposition Studies by Next-Generation Impactor}

Fig. 7 illustrates the deposition of VRC at various stages of the impactor, indicating maximum

(i.e., cutoff of $2.08 \mu \mathrm{m}$ ) of the impactor. The MMAD and GSD were found to be $3.40 \pm 0.27$

$247 \mu \mathrm{m}$ and $2.14 \pm 0.10 \mu \mathrm{m}$, respectively, with $49.30 \pm 3.66 \%$ of dose emitted from the nebulizer and $40.00 \pm 2.47 \%$ of FPF. The observed MMAD was found to be less $4 \mu \mathrm{m}$, construing that the nebulization of model drug exhibits targeting potential in the airways, primarily by the mechanism of sedimentation and diffusion $(1,36)$. In this context, a GSD of $>1.2$ known to

251 indicate a heterodisperse aerosol size distribution, in accordance with the results generally 252 observed with most of the other aerosols (37-39). 


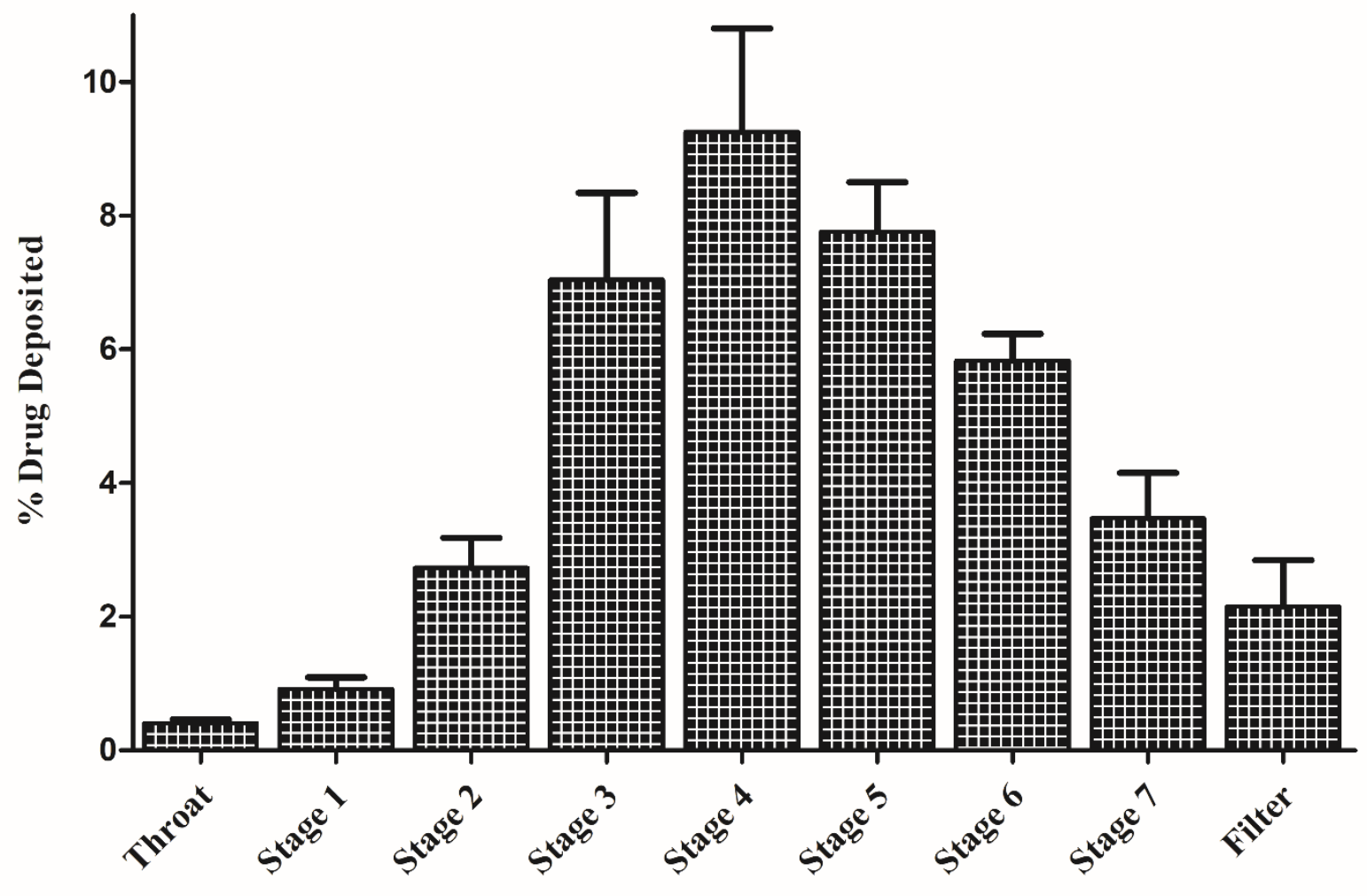

Fig. 7: In vitro pulmonary deposition studies on percentage of voriconazole deposition using a next generation impactor at $15 \mathrm{~L} \mathrm{~min}^{-1}$. Each crossbar indicates $1 \mathrm{SD}$.

\section{Determination of Air-flow at each Delivery Port}

257 The airflow observed at each delivery port was found to be quite consistent, i.e., close to 4.21

$258 \pm 0.13 \mathrm{~L} / \mathrm{min}$ at each outlet, when the other two outlets were closed. This could be attributed to 259 the uniformity maintained by the three-way splitter in delivering the aerosolized drug to each 260 delivery port of the animal holding chamber. Further, the air reaching at all the delivery ports 261 could be analyzed by dividing the above value by number of delivery ports (i.e., 3) which is $1.40 \pm 0.13 \mathrm{~L} / \mathrm{min}$ at each delivery port.

\section{In vitro Optimisation}

Before the start of the experiment, the nebulizer was primed for 1 minute to saturate the central

265 chamber and to maintain a steady flow to the delivery port. The in vitro test conducted with

266 cotton balls revealed the enhancement in the weight of cotton balls by small increments of 5.42

$267 \pm 0.18 \mathrm{mg}$. A total of $10 \mathrm{~mL}$ solution was nebulized initially, out of which $5.17 \pm 0.25 \mathrm{~mL}$ was 
remaining after nebulization of 20 minutes. An amount of $2.05 \pm 0.20 \mathrm{mg}(14.5 \%)$ of VRC was

269

270

271

272

273

274

275

276

277

recovered at the highest concentration tested $(3 \mathrm{mg} / \mathrm{mL})$ at each of the delivery ports with a coefficient of variation less than $18 \%$. In total, $6.12 \pm 0.60 \mathrm{mg}$ drug $(43.4 \%)$ was available at all of the delivery ports with $14.10 \pm 0.15 \mathrm{mg}$ of total drug nebulized and $15.90 \pm 0.75 \mathrm{mg}$ of total amount corresponds to dead dose in the nebulizer. The dose recovered has been 10 -folds and 1.2-folds higher than the previously reported articles $(10,14)$. Fig. 8 presents the VRC fraction obtained across each delivery port, connected to a central chamber through the mouthpiece. As observed, the fraction of VRC recovered increases in the holding chambers, as the concentration approaches towards maximum. Moreover, it was noted that the relative mass fraction did not vary substantially among the three-exposure ports at each of the concentration tested ( $p>0.05$ ), evidently owing to the equidistant position of all the holding chambers with respect to the central chamber.

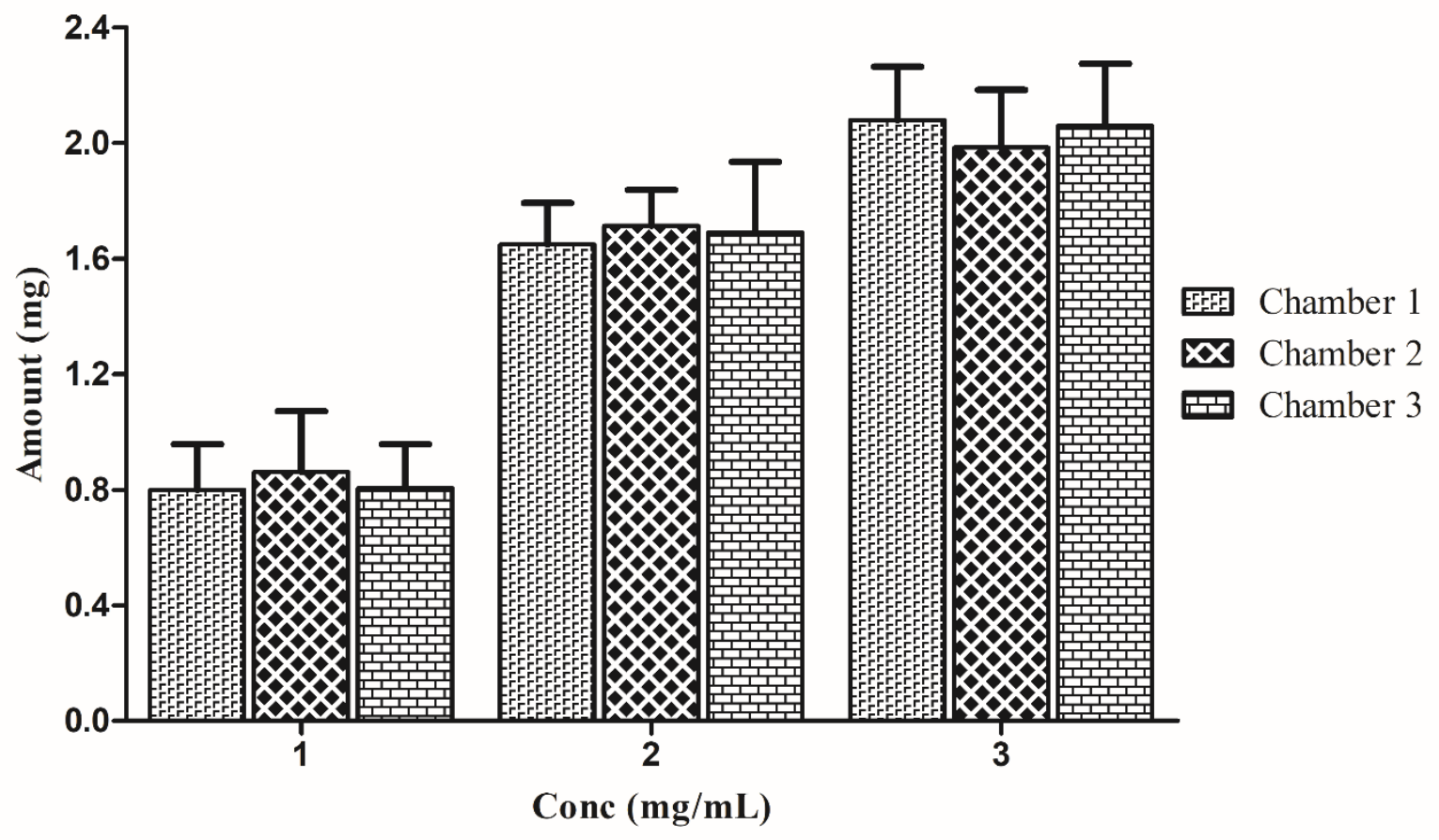

Fig. 8: Optimisation of dose available at each of the delivery ports at varied concentrations of voriconazole. Each crossbar indicates $1 \mathrm{SD}$. 
Fig. 9 illustrates the biodistribution profile of VRC in the lungs following inhalation using a nebulizer. An amount of $76.12 \pm 19.50 \mu \mathrm{g}(3.81 \pm 0.97 \%)$ of VRC was deposited in the whole lungs following nebulization for 20 minutes (Table 1), followed by a declining trend up to $6 \mathrm{~h}$. This could be attributed to the fast rate of drug diffusion of the previously solubilized VRC molecule, large alveolar surface area and thin physiological membrane in the lungs. Therefore, the results substantiate the successful application of the developed inhaler device in the nebulization of VRC microdroplets in mice lungs.

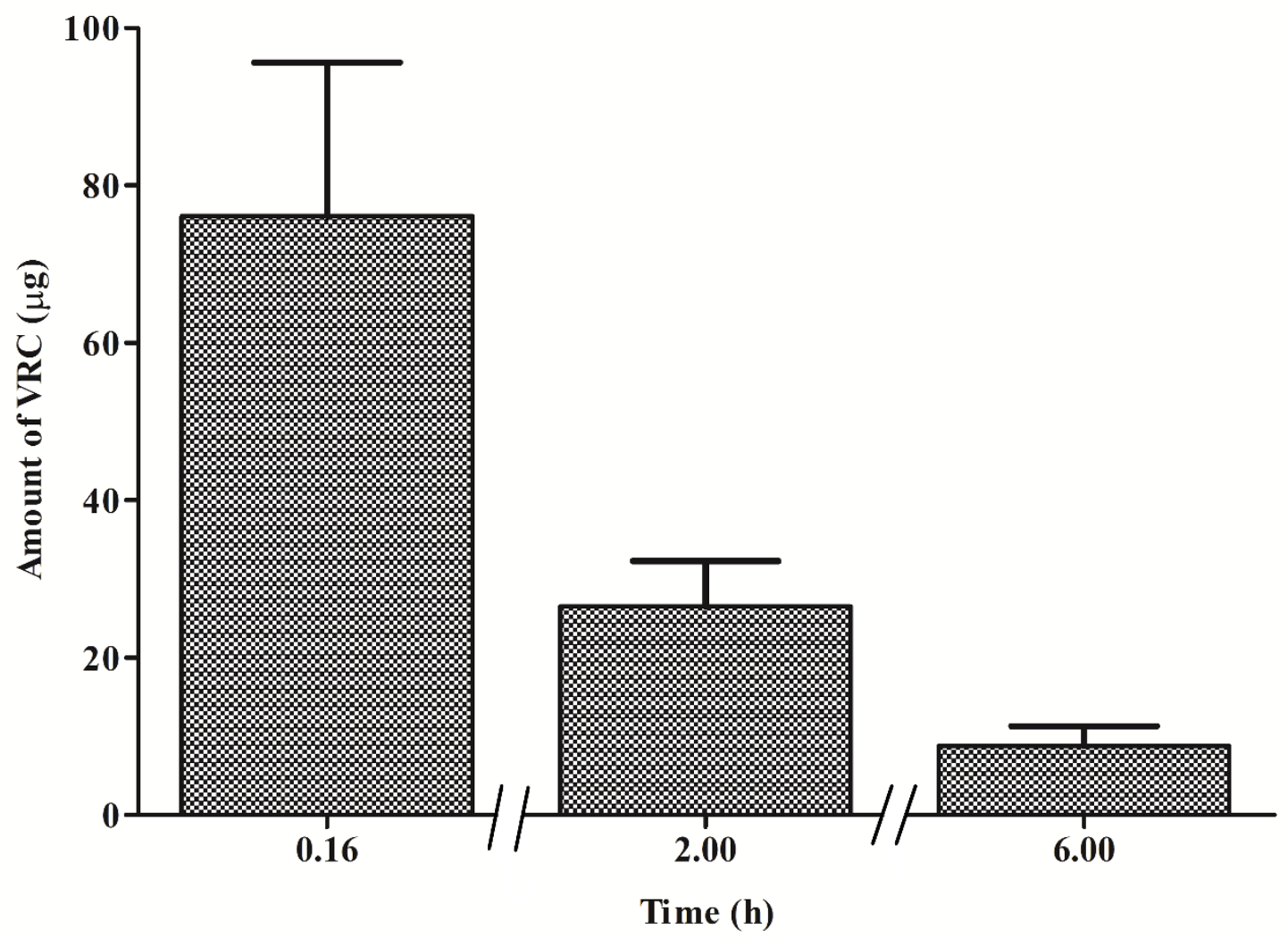

Fig. 9: Lung distribution profile of voriconazole in mice lungs after nebulization for 294 20 minutes. Each crossbar indicates 1 SD. 
Table I: Data pertaining to the emitted and inhaled drug dose.

\begin{tabular}{|c|c|}
\hline Parameter(s) & Mean \pm SD \\
\hline Initial dose in nebulizer $(\mathrm{mg})$ & $30.00 \pm 0.12$ \\
\hline Emitted dose $(\mathrm{mg})$ & $14.10 \pm 0.15$ \\
\hline Dose available at each delivery port $(\mathrm{mg})$ & $2.05 \pm 0.20$ \\
\hline Percent of drug available for inhalation $(\%)$ & $14.53 \pm 1.28$ \\
\hline Dose deposited in mice lungs $(\mu \mathrm{g})$ & $76.12 \pm 19.50$ \\
\hline Percent in vivo deposited $(\%)$ & $3.80 \pm 0.97$ \\
\hline
\end{tabular}

\section{CONCLUSIONS}

The present study demonstrates the development of a simple, cheap and efficient nose-only inhalational chamber for routine analysis of the aerosols, generated through nebulization for use in rodents (20-25 g). Reliability of the inhalation chamber was validated, attributable to the uniform distribution $(\mathrm{p}>0.05)$ of the test particles across the three-delivery ports. Moreover, reduction in the area of the central chamber reduces drug wastage, thus economizing the cost for highly expensive drugs like VRC and anticancer drugs. Further, the apparatus could prove to be a promising tool for preclinical testing of drugs per se or their novel formulations, administered through nebulization at the laboratory scale. Moreover, the device can also be opted for short-or long-term toxicological investigations in rodents. The benefits of the device can also be subsequently extended for usage in larger rodents (around 250g) by just switching over to animal restrainers.

\section{CONFLICT(S) OF INTEREST}

The authors confirm no conflict of interest.

\section{ACKNOWLEDGMENTS}

R.K. is grateful to the Commonwealth Scholarship Commission (CSC) for selecting her as a Commonwealth split-site scholar during the year 2017-2018 and providing the grants to carry out the work on inhalational drug delivery at University of Central Lancashire, Preston, UK. 
University Grants Commission (UGC), India, is gratefully acknowledged for providing financial grants to the Research Fellow (R.K.) under UGC-BSR Scheme. The authors also appreciate M/s Panacea Biotech, New Delhi, India, for supplying the samples of VRC ex-gratis.

\section{REFERENCES}

1. Kaur R, Kaur R, Singh C, Kaur S, Goyal AK, Singh KK, et al. Inhalational drug delivery in pulmonary aspergillosis. Crit Rev Ther Drug Carrier Syst. 2019;36(3):183-17.

2. Labiris NR, Dolovich MB. Pulmonary drug delivery. Part I: Physiological factors affecting therapeutic effectiveness of aerosolized medications. Br J Clin Pharmacol. 2003;56(6):58899.

3. Younis US, Vallorz E, Addison KJ, Ledford JG, Myrdal PB. Preformulation and evaluation of tofacitinib as a therapeutic treatment for asthma. AAPS PharmSciTech. 2019;20(5):167.

4. Ibrahim M, Verma R, Garcia-Contreras L. Inhalation drug delivery devices: Technology update. Med Devices (Auckland, NZ). 2015;8:131.

5. Pirozynski M, Sosnowski TR. Inhalation devices: From basic science to practical use, innovative vs generic products. Expert Opin Drug Deliv. 2016;13(11):1559-71.

6. Moon C, Smyth HDC, Watts AB, Williams RO. Delivery technologies for orally inhaled products: An update. AAPS PharmSciTech. 2019;20(3):117.

7. Phalen RF, Mannix RC, Drew RT. Inhalation exposure methodology. Environ Health Perspect. 1984;56:23-34.

8. Guillon A, Sécher T, Dailey LA, Vecellio L, de Monte M, Si-Tahar M, et al. Insights on animal models to investigate inhalation therapy: Relevance for biotherapeutics. Int $\mathbf{J}$ Pharm. 2018;536(1):116-26.

9. Pauluhn J. Validation of an improved nose-only exposure system for rodents. J Appl Toxicol. 1994;14(1):55-62.

10. Kaur J, Muttil P, Verma RK, Kumar K, Yadav AB, Sharma R, et al. A hand-held apparatus for "nose-only" exposure of mice to inhalable microparticles as a dry powder inhalation targeting lung and airway macrophages. Eur J Pharm Sci. 2008;34(1):56-65.

11. Morcol T, Weidner JM, Mehta A, Bell SJD, Block T. Calcium phosphate particles as pulmonary delivery system for interferon-alpha in mice. AAPS PharmSciTech. 2018;19(1):395-12.

12. Denkers ND, Seelig DM, Telling GC, Hoover EA. Aerosol and nasal transmission of chronic wasting disease in cervidized mice. J Gen Virol. 2010;91(6):1651-58.

13. Sinha B, Mukherjee B. Development of an inhalation chamber and a dry powder inhaler device for administration of pulmonary medication in animal model. Drug Dev Ind Pharm. 2012;38(2):171-79.

14. Mainelis G, Seshadri S, Garbuzenko OB, Han T, Wang Z, Minko T. Characterization and application of a nose-only exposure chamber for inhalation delivery of liposomal drugs and nucleic acids to mice. J Aerosol Med Pulm Drug Deliv. 2013;26(6):345-54.

15. Cannon WC, Blanton EF, McDonald KE. The flow-past chamber: An improved nose-only exposure system for rodents. Am Ind Hyg Assoc. 1983;44(12):923-28. 
16. Camara SA. Manual de farmacologia prática. Manual de farmacologia prática; 1967.

17. Carlini E. Farmacologia prática sem aparelhagem. Farmacologia prática sem aparelhagem; 1973.

18. Komiya M, Takeuchi T, Harada E. Lemon oil vapor causes an anti-stress effect via modulating the 5-HT and DA activities in mice. Behav Brain Res. 2006;172(2):240-49.

19. Ito K, Ito M. Sedative effects of vapor inhalation of the essential oil of Microtoena patchoulii and its related compounds. J Nat Med. 2011;65(2):336-43.

20. Bradley BF, Starkey NJ, Brown SL, Lea RW. The effects of prolonged rose odor inhalation in two animal models of anxiety. Physiol Behav. 2007;92(5):931-38.

21. Shaw D, Annett JM, Doherty B, Leslie JC. Anxiolytic effects of lavender oil inhalation on open-field behaviour in rats. Phytomedicine. 2007;14(9):613-20.

22. Yi J, Chen BT, Schwegler-Berry D, Frazer D, Castranova V, McBride C, et al. Wholebody nanoparticle aerosol inhalation exposures. J Vis Exp. 2013(75):e50263-e.

23. Chen LC, Lippmann M. Inhalation toxicology methods: The generation and characterization of exposure atmospheres and inhalational exposures. Curr Protoc Toxicol. 2015;63:1-23.

24. Silva ER, Bizzo HR, Fernandes PD, Veiga JVF, Leitao SG, Oliveira DR. Development and evaluation of an inhalation chamber for in vivo tests. An Acad Bras Cienc. 2017;89(3):1643-53.

25. Stone BR, Heimbuch BK, Wu CY, Wander JD. Design, construction and validation of a nose-only inhalation exposure system to measure infectivity of filtered bioaerosols in mice. J Appl Microbiol. 2012;113(4):757-66.

26. Nadithe V, Rahamatalla M, Finlay WH, Mercer JR, Samuel J. Evaluation of nose-only aerosol inhalation chamber and comparison of experimental results with mathematical simulation of aerosol deposition in mouse lungs. J Pharm Sci. 2003;92(5):1066-76.

27. Nasr M, Taha I, Hathout RM. Suitability of liposomal carriers for systemic delivery of risedronate using the pulmonary route. Drug Deliv. 2013;20(8):311-18.

28. Kwong WT, Ho SF, Coates AL. Comparison of nebulized particle size distribution with Malvern laser diffraction analyzer versus Andersen cascade impactor and low-flow Marple personal cascade impactor. J Aerosol Med. 2000;13(4):303-14.

29. Abdelrahim ME. Aerodynamic characteristics of nebulized terbutaline sulphate using the Andersen Cascade impactor compared to the Next Generation Impactor. Pharm Dev Technol 2011;16(2):137-45.

30. MMADcalculator. http://www.mmadcalculator.com. [cited 20195 Nov].

31. Shi S, Ashley EF, Alexander BF, Hickey AJ. Initial characterization of micafungin pulmonary delivery via two different nebulizers and multivariate data analysis of aerosol mass distribution profiles. AAPS PharmSciTech. 2009;10(1):129-37.

32. CopleyScientific. https://www.copleyscientific.com/home/inhaler-testing/delivered-doseuniformity/introduction-to-delivered-dose-uniformity-ddu. [cited $20195 \mathrm{Nov}$ ].

33. Ben-Jebria A, Eskew ML, Edwards DA. Inhalation system for pulmonary aerosol drug delivery in rodents using large porous particles. Aerosol Sci Tech. 2000;32(5):421-33. 
34. Pauluhn J, Thiel A. A simple approach to validation of directed flow nose-only inhalation chambers. J Appl Toxicol. 2007;27(2):160-67.

35. Cairns WRL, Barbante C, Capodaglio G, Cescon P, Gambaro A, Eastgate A. Performance characteristics of a low volume spray chamber with a micro-flow nebulizer for ICP-MS. J Anal Atom Spectrom. 2004;19(2):286-91.

36. Jabbal S, Poli G, Lipworth B. Does size really matter? Relationship of particle size to lung deposition and exhaled fraction. J Allergy Clin Immunol 2017;139(6):2013-4.e1.

37. Hickey AJ, Mansour HM. Inhalation aerosols: Physical and biological basis for therapy. $3^{\text {rd }}$ ed. CRC press; 2019.

38. Aramendia I, Fernandez-Gamiz U, Lopez-Arraiza A, Rey-Santano C, Mielgo V, Basterretxea FJ, et al. Experimental evaluation of perfluorocarbon aerosol generation with two novel nebulizer prototypes. Pharmaceutics. 2019;11(1):19.

39. Berlinski A, Waldrep JC. Nebulized drug admixtures: Effect on aerosol characteristics and albuterol output. J Aerosol Med. 2006;19(4):484-90. 